\title{
Alimentação de leitões na creche com dietas sem aditivos antimicrobianos, com alho (Allium sativum, L.) ou colistina
}

\author{
Feeding of piglets in post weaning with diets without microbian additives, \\ with garlic (Allium sativum, L.) or colistin
}

\author{
Paulo Alberto Lovatto ${ }^{1}$ Vladimir de Oliveira ${ }^{2}$ Lucélia Hauptli ${ }^{3}$ \\ Luciano Hauschild ${ }^{4}$ Marcus Macedo Cazarré ${ }^{5}$
}

\section{RESUMO}

Foi realizado um experimento para estudar o desempenho de leitões, dos 35 aos 62 dias de idade, alimentados com dietas sem aditivos, com alho ou com colistina. Noventa e seis leitões foram distribuídos em quatro tratamentos num desenho experimental de blocos inteiramente casualizados. A dieta controle (DC) não continha aditivos anti-microbianos; as dietas dois e três foram constituídas pela DC mais $0,05 \%$ e $0,15 \%$ de alho em pó, respectivamente; a dieta quatro continha a DC mais $0,25 \%$ de sulfato de colistina. O consumo de ração foi $16,2 \%$ maior $(P<0,05)$ para os animais alimentados com dietas contendo colistina que aqueles que consumiram dietas contendo $0,05 \%$ de alho. Não houve diferenças entre os animais que consumiram colistina e aqueles alimentados sem aditivos ou com $0,015 \%$ de alho na dieta. O ganho de peso foi maior $(P<0,05)$ para os animais alimentados com dietas contendo colistina. Não houve diferença de ganho de peso entre os animais que consumiram dietas sem aditivos e contendo alho. Os animais alimentados com dietas contendo de alho tiveram conversões alimentares médias ao redor de $7 \%$ piores $(P>0,05)$ que os animais alimentados com colistina. $\mathrm{O}$ uso de dietas sem antimicrobianos ou com alho para leitões na creche não permite alcançar os mesmos resultados que dietas contendo colistina.

Palavras-chave: alho, antimicrobianos, leitões, nutrição, promotores de crescimento.

\section{ABSTRACT}

An experiment was carried out to evaluate piglet performance, ranging from 35 to 62 days of age, fed with diets with no growth parameters, with the addition of garlic and colistina in diets. Ninety-six piglets were distributed in four treatments in a complete randomized block design. The treatments were: control diet, without anti-microbials (DC); diet two: $D C+0.05 \%$ of powder garlic; diet three: $D C+$ $0.15 \%$ of powder garlic; diet four: $D C+0.25 \%$ of colistina sulfate. Feed intake was $16.2 \%$ higher $(P<0.05)$ for the animals fed with the diet containing colistina compared to the diet containing $0.05 \%$ of powder garlic. There were no differences in animal performance when pigs were fed with diets containing $0.25 \%$ of colistine, $0.15 \%$ of powder garlic or only without anti-microbials. Weight gain was higher $(P<0.05)$ for animals fed with diets with colistine. There was not difference in weight gain between animals fed with diets without or with garlic. Piglets fed with garlic diets had $7 \%$ worse feed conversion $(P>0.05)$ than animals fed with the diet with colistine. In conclusion, diets without anti-microbial or with powder garlic can not replace diets with colistine sulfate when fed to piglets during the post weaning phase.

Key words: anti-microbial, garlic, growth promoters, nutrition, piglets.

\section{INTRODUÇÃO}

No sistema confinado de produção de suínos, o período mais crítico para criação dos animais vai do nascimento ao final da creche. A redução do período lactacional, associado à imaturidade digestiva dos leitões, fez com que técnicos e produtores utilizassem controladores sintéticos de microorganismos no trato digestivo. Desde 1949, utilizam-se antibióticos na produção animal para

\footnotetext{
${ }^{1}$ Veterinário, Professor Adjunto, Departamento de Zootecnia, Universidade Federal de Santa Maria (UFSM), 97105-900, Santa Maria, RS, Brasil. E-mail: lovatto@smail.ufsm.br

${ }^{2}$ Zootecnista, Professor Adjunto, Universidade do Oeste do Paraná, Marechal Cândido Rondon, PR, Brasil.'

${ }^{3}$ Zootecnista, Mestrando do Programa de Pós-graduação em Zootecnia, UFSM, Brasil.

${ }^{4}$ Acadêmico de Zootecnia, UFSM, Bolsista de Iniciação Científica da Fundação da Amparo à Pesquisa do Rio Grande do Sul (FAPERGS)

${ }^{5}$ Zootecnista, MSc, Concórdia, SC, Brasil.
} 
estimular o crescimento, prevenir e controlar doenças (JUKES, 1972).

O uso de antibióticos na alimentação animal justifica-se pela maior taxa de crescimento, melhor conversão alimentar e redução da mortalidade por infecções clínicas e sub-clínicas. As melhorias observadas se devem, provavelmente, ao controle de microorganismos não identificados e moderadamente patogênicos que colonizam o trato gastrintestinal (NAGANAWA et al., 1996; AVATO et al., 2000).

No entanto, a maioria dos antibióticos usados como aditivos na alimentação animal foi proibida na Europa em 1999, pois poderiam estimular resistência cruzada com patógenos humanos (LAVAL, 1999; BOERLIN et al., 2001). Existe interesse no Brasil em se identificar novos ingredientes que possam substituir os antibióticos sintéticos, sem a perda no desenvolvimento do animal (FREITAS et al., 2001).

A redução do uso de antibióticos sintéticos como "promotores de crescimento" de suínos estimulou as pesquisas de "alternativas naturais". Dentre as quais está o alho (Allium sativum, $L$ ), cujas propriedades são conhecidas há muito tempo (CAVALLITO \& BAILEY, 1944). Na alimentação humana, o consumo de alho se deve a atividades biológicas, tais como as antimicrobianas, antiesclerosegênicas e antitóxicas. O alho é rico em componentes organossulfurados que, acredita-se, sejam responsáveis por essas atividades. No caso da alimentação de suínos, a inclusão de alho na ração favorece a secreção gástrica, aumentando a eficiência da barreira antimicrobiana o que pode prevenir infecções microbianas gastrintestinais (DELMING \& KOCH, 1974). Em suínos em crescimento, esses efeitos do alho melhoram o ganho de peso, a eficiência alimentar, podendo ele ser utilizado por períodos prolongados, sem que as características organolépticas da carne sejam alteradas (DONZELE et al., 1978; PICOLLO et al., 1979).

No entanto, as informações disponíveis sobre a inclusão de alho em dietas na fase de creche são escassas. Este trabalho tem, portanto, o objetivo de estudar os efeitos da alimentação de leitões na creche com dietas sem aditivos, com alho ou colistina.

\section{MATERIAL E MÉTODOS}

O trabalho foi realizado no Setor de Suinocultura do Departamento de Zootecnia da Universidade Federal de Santa Maria. Foram utilizados 96 leitões homogêneos geneticamente, oriundos de criação comercial e desmamados aos 21 dias de idade. O experimento iniciou após uma fase pré-experimental de 14 dias. Os leitões foram alojados em 24 baias elevadas medindo 1,50 x 1,37 x 0,80m, com piso parcialmente ripado e equipadas com comedouros semi-automáticos e bebedouros tipo concha. A temperatura da sala-creche foi mantida dentro da zona de conforto térmico recomendada para a fase.

Os animais foram distribuídos em quatro tratamentos $(\mathrm{T} 1=$ Dieta controle; $\mathrm{T} 2=\mathrm{T} 1+0,05 \%$ de alho em pó; $\mathrm{T} 3$ = T1 + 0,15\% de alho em pó; T4 = $\mathrm{T} 1+0,25 \%$ de sulfato de colistina) com seis repetições e quatro animais por unidade experimental. As unidades experimentais foram distribuídas nos tratamentos, seguindo um delineamento inteiramente casualizado. As rações experimentais (Tabela 1) foram isonutritivas, elaboradas com milho e farelo de soja, formuladas de acordo com o NRC (1988) e fornecidas à vontade. $\mathrm{O}$ alho em pó utilizado foi uma preparação desidratada obtida a partir do produto natural que contém cerca de $40 \%$ de matéria seca (LAWSON, 1996).

Os dados de ganho diário de peso foram obtidos por pesagens semanais individuais dos animais; os referentes ao consumo diário de ração pela pesagem da ração fornecida menos os resíduos presentes nos comedouros. Os dados foram analisados através do programa MINITAB (MCKENZIE \& GOLDMAN, 1999) para variância, teste F e, quando houve diferenças significativas, teste de Tukey. Foram incluídos no modelo o tratamento e sexo como variáveis independentes.

Tabela 1 - Composição centesimal das rações experimentais ${ }^{1}$

\begin{tabular}{|c|c|c|c|}
\hline \multirow{2}{*}{ Ingredientes } & \multicolumn{3}{|c|}{ Períodos } \\
\hline & $1(35-43 \mathrm{~d})$ & $2(44-52 d)$ & $3(53-62 d)$ \\
\hline Milho & 49,49 & 58,25 & 67,05 \\
\hline Farelo de soja & 23,50 & 25,80 & 27,90 \\
\hline Óleo de soja & 3,23 & 1,75 & 1,75 \\
\hline Premix vit/min & 3,00 & 2,48 & 3,00 \\
\hline Núcleo & 20,00 & 10,00 & - \\
\hline Alho $^{2}$ & - & - & - \\
\hline Sulfato de colistina $^{2}$ & - & - & - \\
\hline DL-metionina & 0,06 & 0,17 & \\
\hline L-Lisina & 0,41 & 0,17 & \\
\hline Sal & 0,30 & 0,30 & 0,30 \\
\hline
\end{tabular}

${ }^{1}$ As rações pré-experimentais continham: Período 1: PB 20\%, EM $3350 \mathrm{kcal} / \mathrm{kg}$, Lisina 1,4\%, Ca 1,04\%, P 0,72\%. Período 2: PB 19\%, EM $3350 \mathrm{kcal} / \mathrm{kg}$, lisina 1,14\%, Ca 0,95\%, P 0,67\%. Período 3: PB 18\%, EM $3350 \mathrm{kcal} / \mathrm{kg}$, lisina 0,94\%, Ca 0,84\%, P 0,63\%; ${ }^{2}$ adicionados de acordo com os tratamentos 


\section{RESULTADOS E DISCUSSÃO}

Os valores de consumo de ração são apresentados na tabela 2. Os consumos de ração médios foram diferentes $(\mathrm{P}<0,05)$ no segundo período e no período total. No período compreendido entre 44 e 52 dias de idade, os leitões alimentados com a dieta contendo colistina consumiram 19,1\% mais ração que os animais alimentados com as rações contendo alho. Os leitões alimentados com a ração controle apresentaram consumo semelhante $(\mathrm{P}>0,05)$ aos demais tratamentos. $\mathrm{O}$ consumo de ração médio dos três períodos estudados foi $16,2 \%$ maior $(\mathrm{P}<0,05)$ para os leitões alimentados com dietas contendo colistina, comparado àqueles que consumiram dietas contendo $0,05 \%$ de alho. As rações sem aditivo e com $0,15 \%$ de alho propiciaram consumos semelhantes $(\mathrm{P}>0,05)$ aos observados nos demais tratamentos.

Os resultados obtidos no presente estudo contrariam aqueles de DONZELE et al. (1978) e HORTON et al. (1991) que mostraram que dietas contendo até $0,168 \%$ de alho não afetavam o consumo de alimento. A redução no consumo de ração observada nos animais alimentados com dietas contendo alho não é amparada na literatura. Uma hipótese a ser considerada para esse efeito é a presença no alho de propriedades ou princípios que deprimem a ingestão voluntária, mas isso não foi confirmada em estudos sobre o tema (LAWSON, 1996).

Os valores de ganho de peso dos leitões são apresentados na tabela 3. Houve diferenças significativas $(\mathrm{P}<0,05)$ no terceiro período (53-62 dias) e no período total (35-62 dias). No período compreendido entre 53 e 62 dias de idade, os animais alimentados com dietas contendo colistina tiveram um ganho de peso diário médio 18\% superior aos animais

Tabela 2 - Consumo de ração (kg/dia) de leitões na creche alimentados com dietas sem aditivos, com alho ou colistina

\begin{tabular}{lcccc}
\hline \multirow{2}{*}{ Parâmetro } & \multicolumn{4}{c}{ Idade, dias } \\
\cline { 2 - 5 } & $35-43$ & $44-52$ & $53-62$ & $35-62$ \\
\hline Testemunha, T1 & 0,677 & $0,957^{\mathrm{ab}}$ & 1,193 & $0,942^{\mathrm{ab}}$ \\
T1 + 0,05\% alho & 0,650 & $0,855^{\mathrm{a}}$ & 1,140 & $0,882^{\mathrm{a}}$ \\
T1 + 0,15\% alho & 0,623 & $0,892^{\mathrm{a}}$ & 1,245 & $0,920^{\mathrm{ab}}$ \\
T1 + 0,25\% colistina & 0,732 & $1,018^{\mathrm{b}}$ & 1,325 & $1,025^{\mathrm{b}}$ \\
\hline dpr & 0,075 & 0,062 & 0,130 & 0,075 \\
\hline Efeito* & $\mathrm{NS}$ & $\mathrm{T}$ & $\mathrm{NS}$ & $\mathrm{T}$
\end{tabular}

dpr, desvio padrão residual; NS, não significativo; T, tratamento; *nível de significância 5\%; ${ }^{\text {a, b}}$ Médias na mesma coluna seguidas de letras iguais não são diferentes
Tabela 3 - Ganho de peso ( $\mathrm{kg} / \mathrm{dia})$ de leitões na creche alimentados com dietas sem aditivos, com alho ou colistina

\begin{tabular}{lllll}
\hline \multirow{2}{*}{ Parâmetro } & \multicolumn{4}{c}{ Idade, dias } \\
\cline { 2 - 5 } & $35-43$ & $44-52$ & $53-62$ & $35-62$ \\
\hline Testemunha, T1 & 0,334 & 0,498 & $0,508^{\mathrm{a}}$ & $0,447^{\mathrm{a}}$ \\
T1 + 0,05\% alho & 0,320 & 0,468 & $0,443^{\mathrm{a}}$ & $0,410^{\mathrm{a}}$ \\
$\mathrm{T} 1+0,15 \%$ alho & 0,327 & 0,429 & $0,507^{\mathrm{a}}$ & $0,421^{\mathrm{a}}$ \\
$\mathrm{T} 1+0,25 \%$ colistina & 0,398 & 0,509 & $0,599^{\mathrm{b}}$ & $0,502^{\mathrm{b}}$ \\
\hline dpr & 0,097 & 0,085 & 0,109 & 0,069 \\
\hline Efeito* & $\mathrm{NS}$ & $\mathrm{NS}$ & $\mathrm{T}$ & $\mathrm{T}$ \\
\hline
\end{tabular}

dpr, desvio padrão residual; NS, não significativo; T, tratamento; *nível de significância 5\%; ${ }^{\text {a, b}}$ Médias na mesma coluna seguidas de letras iguais não são diferentes

alimentados com ração sem aditivos e com 0,15\% de alho. Essa diferença foi de $35 \%$ quando comparada aos animais que consumiram dietas contendo $0,05 \%$ de alho. Não houve diferença $(P>0,05)$ de ganho de peso diário médio entre os animais que consumiram dietas sem aditivos e contendo alho.

Os ganhos de peso, sobretudo dos animais alimentados com dietas contendo alho, foram baixos em relação aos animais alimentados com dietas contendo colistina. Estudos mostraram que componentes organossulfurados do alho atuam sobre bactérias do trato gastrintestinal em humanos (O'GARA et al., 2000) e têm um papel na modulação do sistema antioxidante ligado à glutationa no fígado e nas células vermelhas de ratos (WU et al., 2001). Esses efeitos, transpostos ao suíno, poderiam teoricamente melhorar o ganho de peso com dietas contendo alho, pois reduziriam a população bacteriana no trato gastrintestinal e melhorariam o sistema oxidativo das células hepáticas e hemácias. Além disso não ocorrer, os animais alimentados com a menor menor nível de inclusão de alho perderam mais peso em relação aos alimentados com dietas contendo colistina. Esse ganho inferior pode ter sido conseqüência do menor consumo de alimento. Um outro aspecto que deve ser levado em conta no ganho de peso é a fase de desenvolvimento dos animais, pois a acidez gástrica aumenta a atividade antimicrobiana dos constituintes do alho (FORTUNATOV, 1955). Na fase de creche, os leitões têm $\mathrm{pH}$ gástrico elevado em relação à idade adulta, o que poderia reduzir os efeitos antimicrobianos do alho.

Os valores de conversão alimentar dos leitões são apresentados na tabela 4. Houve diferenças significativas $(\mathrm{P}<0,05)$ somente no terceiro período, no qual os animais alimentados com dietas contendo $0,05 \%$ de alho tiveram uma piora na conversão alimentar de 
Tabela 4 - Conversão alimentar de leitões na creche alimentados com dietas sem aditivos, com alho ou colistina

\begin{tabular}{lcccc}
\hline \multirow{2}{*}{ Parâmetro } & \multicolumn{4}{c}{ Idade, dias } \\
\cline { 2 - 5 } & $35-43$ & $44-52$ & $53-62$ & $35-62$ \\
\hline Testemunha, T1 & 2,089 & 1,952 & $2,355^{\mathrm{bc}}$ & 2,112 \\
$\mathrm{~T} 1+0,05 \%$ alho & 2,298 & 1,910 & $2,817^{\mathrm{a}}$ & 2,218 \\
$\mathrm{~T} 1+0,15 \%$ alho & 2,027 & 2,174 & $2,530^{\mathrm{bc}}$ & 2,243 \\
$\mathrm{~T} 1+0,25 \%$ colistina & 1,910 & 2,041 & $2,257^{\mathrm{bc}}$ & 2,070 \\
\hline dpr & 0,553 & 0,423 & 0,567 & 0,324 \\
\hline Efeito* & $\mathrm{NS}$ & $\mathrm{NS}$ & $\mathrm{T}$ & $\mathrm{NS}$ \\
\hline
\end{tabular}

dpr, desvio padrão residual; NS, não significativo; T, tratamento; "nível de significância 5\%; ${ }^{\text {a, b}}$ Médias na mesma coluna seguidas de letras iguais não são diferentes

aproximadamente 25, 20 e 11\% em relação aos animais alimentados com dietas contendo colistina, sem aditivos e com $0,15 \%$ de alho, respectivamente. No entanto, as conversões alimentares médias de todo o período experimental não diferiram significativamente entre si.

Embora não tenha havido diferença significativa entre os tratamentos estudados para a conversão alimentar média do experimento, as diferenças numéricas foram importantes. Os animais alimentados com dietas contendo alho tiveram conversões alimentares médias ao redor de $7 \%$ piores que os animais alimentados com colistina. A não significância entre os resultados se deve à elevada variabilidade dentro das unidades experimentais, sobretudo nos animais alimentados com dietas sem aditivos ou contendo alho. Do ponto de vista teórico, o alho deveria melhorar o ambiente gastrintestinal através de ações antimicrobianas, o que reduziria a contaminação de microorganismos indesejáveis e aumentaria a digestibilidade dos nutrientes. Isso não aconteceu e os resultados sinalizaram para uma conversão alimentar melhor nos animais alimentados com dietas contendo colistina.

Esse trabalho mostrou que o consumo de ração e o ganho de peso de leitões alimentados na creche com dietas sem aditivos ou contendo alho foram afetados negativamente quando comparados aos animais que receberam ração com colistina.

\section{CONCLUSÃO}

Não se recomenda a inclusão de alho em rações de leitões na fase de creche.

\section{REFERÊNCIAS BIBLIOGRÁFICAS}

AVATO, P. et al. Allylsulfide constituents of garlic volatile oil as antimicrobial agents. Phytomedicine, v.7, p.239243, 2000 .
BOERLIN, P. et al. Antimicrobial growth promoter ban and resistance to macrolides and vancomycin in enterococci from pigs. J Clin Microbiol, v.39, p.4193-4195, 2001.

CAVALLITO, C.J.; BAILEY, J.H. Allicin, the antibacterial principle of Allium sativum. L. Isolation, physical properties and antibacterial action. Journal American Chemistry Society, v.66, p.1950-1954, 1944.

DELMING, L.; KOCH, H. Condiments: the stimbiting effect of pepper, curry, paprika, horseradish, garlic and mustard on gastric acid secretion was examined in the human stomach. Acta HepatoGastroentorology, v.21, p.377-379, 1974.

DONZELE, J.L. et al. Utilização do alho (Allium sativum, L) como estimulante de crescimento dse suínos. Revista Brasileira de Zootecnia, v.7, p.196-207, 1978.

FORTUNATOV, M.N. On the activity of the phytoncides from garlic in the human organism upon peroral administration. Farmakol, Toksikol,. v.18, p.43-46, 1955.

FREITAS, R. et al. Utilização do alho como promotor de crescimento de frangos de corte. Revista Brasileira de Zootecnia, v.30, p.761-765, 2001.

HORTON, G.M.J. et al. The effect of garlic (Allium sativum) on feed palatability of horses and feed consumption, selected performance and blood parameters in sheep and swine. Canadian Journal of Animal Science, v.71, p.607, 1991.

JUKES, T.H. Antibiotics in animal feeds and animal production. Bioscience v.22, p.526-534, 1972.

LAVAL, A. Use of antibiotics in swine production: advantages and limits. The problem of antibioresistence. In: CONGRESSO BRASILEIRO DE VETERINÁRIOS ESPECIALISTAS EM SUÍNOS, 9., 1999, Belo Horizonte. Anais... Belo Horizonte : ABRAVES, 1999. p.119-130.

LAWSON, L.D. The composition and chemistry of garlic cloves and processed garlic. In: KOCK, H.P.; LAWSON, L.D. (eds.). The science and therapeutic application of Allium sativum $L$. and related species. 2.ed. Baltimore : Williams and Wilkins, 1996. 329p.

MCKENZIE, J.; GOLDMAN, R.N. The student edition of Minitab for Windows manual: release 12 . Belmont : Addison-Wesley Longman, Softcover,1999. $592 \mathrm{p}$.

NAGANAWA, R. et al. Inhibition of microbial growth by ajoene, a sulfur-containing compound derived from garlic. Appl Environ Microbiol, v.62, p.4238-4242, 1996.

NRC. Nutrient Requirements of Swine. 9.ed. Washington, DC : National Academy, 1988. 90p.

O’GARA, E.A. et al. Activities of garlic oil, garlic powder, and their diallyl constituents against Helicobacter pylori. Appl Environ Microbiol, v.66, p.2269-2273, 2000.

PICOLLO, M. G. et al. Avaliação sensorial da carne de suínos alimentados com rações que continham alho (Allium sativum, L) em substituição a antibióticos. Rev Ceres v.26, p.268-274, 1979.

WU, C.C. et al. Effects of organosulfur compounds from garlic oil on the antioxidation system in rat liver and red blood cells. Food Chem Toxicol, v.39, p.563-569, 2001. 